\title{
THE OCEAN BOMB RADIOCARBON INVENTORY REVISITED
}

\author{
Anne Mouchet \\ Laboratoire des Sciences du Climat et de l'Environnement (LSCE), CEA/CNRS/UVSQ/IPSL, Orme des Merisiers, Gif-sur- \\ Yvette, France. Also: Université de Liège, Astrophysics, Geophysics and Oceanology Department, 17 Allée du Six-Août, \\ 4000 Liège, Belgium. Email: A.Mouchet@ulg.ac.be.
}

\begin{abstract}
Large discrepancies exist among data-based estimates and model reconstructions of the ocean bomb radiocarbon inventory. In order to resolve this gap, it has been proposed that the $\mathrm{CO}_{2}$ piston velocity should be revised downward (Sweeney et al. 2007; Müller et al. 2008). This article compares the transient ${ }^{14} \mathrm{C}$ distributions in the ocean obtained with different formulations of the isotopic ratio commonly used in modeling studies. It is found that both the $\mathrm{CO}_{2}$ increase and the airsea $\mathrm{CO}_{2}$ flux significantly contribute to the 1990 ocean bomb ${ }^{14} \mathrm{C}$ inventory, by around $10 \%$ each. Moreover, these 2 processes explain more than $25 \%$ of the inventory difference between 1974 and 1990 . These results imply that, as already argued by Naegler (2009), inventories based on observations that lack information about $\mathrm{CO}_{2}$ invasion are underestimated. Further, this work provides insight into the reasons for discrepancies among model results. It suggests that while a comprehensive isotopic formulation is needed when addressing the global ${ }^{14} \mathrm{C}$ cycle, a simplified form is more relevant for model calibration and piston velocity assessment based on currently available bomb ${ }^{14} \mathrm{C}$ inventories.
\end{abstract}

\section{INTRODUCTION}

Our ability to predict future Earth climate relies on our understanding of the global carbon cycle as well as of the ocean circulation. Ocean ventilation, i.e. the replacement of interior waters by seawater having been in contact with the atmosphere, is a key climatic process since it controls the rate at which the ocean can sequester excess heat and carbon. On the decadal to centennial timescales, the magnitude of the atmospheric $\mathrm{CO}_{2}$ disturbance is determined by exchange with the terrestrial and surface ocean reservoirs. The radiocarbon released by atmospheric nuclear weapons testing ("bomb" ${ }^{14} \mathrm{C}$ ) is an ideal tracer to gain insight into the specific rates characterizing the carbon cycle and ocean ventilations on such timescales. Assessment of the global distribution of bomb ${ }^{14} \mathrm{C}$ provides constraints on the carbon fluxes between reservoirs (e.g. Hesshaimer et al. 1994; Lassey et al. 1996; Levin et al. 2010). More specifically, it allows determination of the global air-sea gas exchange rate (Wanninkhof 1992; Krakauer et al. 2006; Sweeney et al. 2007; Naegler 2009) and therefore to estimate the net air-sea $\mathrm{CO}_{2}$ flux (Takahashi et al. 2009). It also offers the opportunity to assess near-surface circulation, vertical transport, and mixing schemes in OGCMs (Toggweiler et al. 1989b; Jain et al. 1995; Joos et al. 1997; England and Rahmstorf 1999; Orr et al. 2001; Müller et al. 2006).

For these reasons, a precise knowledge of the ocean bomb ${ }^{14} \mathrm{C}$ inventory is needed. However, this quantity has been long debated and seems elusive. The initial estimate by Broecker et al. (1985) has either been questioned (Hesshaimer et al. 1994; Duffy and Caldeira 1995) or corroborated (Broecker et al. 1995; Lassey et al. 1996). Since then, new methods (e.g. Rubin and Key 2002; Peacock 2004) and field-based measurements (Key et al. 2004) have been made available. With the exception of an increased inventory in the Southern Ocean (Leboucher et al. 1999), recent works based on field studies usually call for a downward revision of the bomb ${ }^{14} \mathrm{C}$ inventory (e.g. Peacock 2004; Sweeney et al. 2007). An important implication of these results is that the air-sea gas exchange rate initially proposed by Wanninkhof (1992) should be significantly reduced: Sweeney et al. (2007) and Müller et al. (2008) suggest reductions by as much as $30 \%$ and $19 \%$, respectively.

The use of bomb ${ }^{14} \mathrm{C}$ as an ocean tracer is not straightforward because the exact amount that entered the sea may only be indirectly obtained. Indeed, except for measurements on corals or seashells, we do not have any direct evidence of pristine ocean values (Broecker et al. 1995; Rubin and Key

(C) 2013 by the Arizona Board of Regents on behalf of the University of Arizona

Proceedings of the 21st International Radiocarbon Conference edited by A J T Jull \& C Hatté

RADIOCARBON, Vol 55, Nr 2-3, 2013, p 1580-1594 


\section{A Mouchet}

2002). Bomb ${ }^{14} \mathrm{C}$ is computed by subtracting the observed (post-bomb) ${ }^{14} \mathrm{C}$ concentrations from an estimate of the natural pre-anthropogenic values (Broecker et al. 1995). The natural ${ }^{14} \mathrm{C}$ is reconstructed on the basis of empirical relationships between $\Delta^{14} \mathrm{C}$ and other tracers (Broecker et al. 1995; Rubin and Key 2002; Peacock 2004; Sweeney et al. 2007). These procedures also necessitate the separation of bomb-free water masses from those already contaminated. This task is performed with the help of transient tracers such as CFCs or tritium or with the help of OGCMs. Other factors significantly contribute to the uncertainty of field-based estimates. First, incomplete spatial and temporal coverage as well as significant delay between data collection in different ocean basins produce biased estimates. The second significant source of uncertainty comes from the fact that bomb inventories are computed on the basis of available DIC samples contemporaneous to $\Delta^{14} \mathrm{C}$ measurements (Key et al. 2004). Hence, data-based inventories probably provide a lower-bound estimate because they neglect the fact that DIC levels were lower in earlier decades (Naegler 2009).

Model studies, on the other hand, do not yet provide a means for solving these difficulties. Bomb ${ }^{14} \mathrm{C}$ ocean inventories as estimated by different models encompass a wide range of values (Joos 1994; Duffy and Caldeira 1995; Joos and Bruno 1998; Müller et al. 2008) and are usually much larger than

data-based inventories. Processes controlling the bomb ${ }^{14} \mathrm{C}$ uptake in the ocean include the air-sea exchange rate but also the renewal rate of surface waters (the ventilation), which is model-dependent. Joos et al. (1997), Joos and Bruno (1998), and Müller et al. (2008) attribute most of the discrepancy to the gas exchange coefficient. Other sources for differences in model predicted values include surface boundary conditions in the Southern Ocean (Toggweiler and Samuels 1993), vertical mixing (Toggweiler et al. 1989b; Müller et al. 2008), or the numerical scheme (Bryan 1987; Duffy et al. 1997).

There is another source of discrepancy among model results that has been overlooked. It is to be found in the way ${ }^{14} \mathrm{C}$ is represented in models (models that sometimes will complement field information to provide data-based estimates; e.g. Naegler et al. 2006; Sweeney et al. 2007). Several model studies adopted the simplified formulation of Toggweiler et al. (1989a) to describe the transport of ${ }^{14} \mathrm{C}$ in the ocean (Maier-Reimer et al. 1993; Stocker et al. 1994; Duffy and Caldeira 1995; Campin et al. 1999; England and Rahmstorf 1999; Rodgers et al. 2000; Mahadevan 2001; Orr et al. 2001; Butzin et al. 2005; Müller et al. 2006). This formulation does not much affect the equilibrium (or pre-industrial) ${ }^{14} \mathrm{C}$ distribution in the ocean (Maier-Reimer 1993; Orr et al. 2001). However, its effect on the ocean bomb ${ }^{14} \mathrm{C}$ uptake might be more significant since it relies on the hypothesis that air-sea $\mathrm{CO}_{2}$ disequilibrium remains constant over the period of interest.

We examine the transient distributions of ${ }^{14} \mathrm{C}$ in the ocean from modeling studies based on different formulations for ${ }^{14} \mathrm{C}$. For this purpose, we use a 3D model of the carbon cycle driven by 2 different circulation fields. Two methods for representing ${ }^{14} \mathrm{C}$ are then implemented in the model. With one formulation all carbon isotopes are transported while with the other $\Delta^{14} \mathrm{C}$ is considered as the state variable. The differences between the results obtained with the 2 methods as well as the implications for estimates of the $\mathrm{CO}_{2}$ gas exchange coefficient based on ${ }^{14} \mathrm{C}$ bomb inventories are examined and discussed. Methods and model setup are presented below. The description of numerical experiments results precedes the general discussion and conclusions.

\section{METHODS}

\section{Modeling Radiocarbon}

A distinction is made between isotopic ratios relative to the number of ${ }^{12} \mathrm{C}$ atoms in the sample $(\Re)$ or to the total number of carbon atoms (R). Hence, we define the ratios ${ }^{13} \mathrm{R}={ }^{13} \mathrm{C} / \mathrm{C},{ }^{14} \mathrm{R}={ }^{14} \mathrm{C} / \mathrm{C}$, and 
${ }^{13} \Re={ }^{13} \mathrm{C} /{ }^{12} \mathrm{C}$. $\mathrm{R}$ is the ratio most readily computed in numerical models while field measurements are usually expressed using the following quantities:

$$
\begin{aligned}
& \delta^{13} C=\left(\frac{{ }^{13} \mathfrak{R}}{{ }^{13} \mathfrak{R}_{P D B}}-1\right) 10^{3}=\left(\frac{{ }^{13} R}{\left(1-{ }^{13} R\right)^{13} \mathfrak{R}_{P D B}}-1\right) 10^{3} \\
& { }^{14} C=\left(\frac{{ }^{14} R}{{ }^{14} R_{\text {OXA }}}\left(\frac{0.975}{1+\delta^{13} C / 10^{3}}\right)^{2}-1\right) 10^{3}
\end{aligned}
$$

in which ${ }^{13} \Re_{\mathrm{PDB}}=1.12372 \times 10^{-2}$ is the PDB standard ratio, ${ }^{14} \mathrm{R}_{\mathrm{OXA}}=1.176 \times 10^{-12}$ the oxalic acid standard, and 0.975 a constant term corresponding to the average terrestrial wood ${ }^{13} \Re$ ratio for the pre-industrial period (Stuiver and Polach 1977; Keeling 1981).

With $\mathbf{u}$ the 3-D velocity field and $K$ the diffusivity tensor, the equations governing the transport of total dissolved inorganic carbon concentration $\mathrm{C}_{\mathrm{T}}$ and that of its isotopes ${ }^{i} \mathrm{C}_{\mathrm{T}}$ (with $i=13$ or 14 ) in the ocean read

$$
\begin{gathered}
\frac{\partial}{\partial t} C_{T}=-\nabla \cdot\left(\mathbf{u} C_{T}-K \cdot \nabla C_{T}\right)+q_{v}\left(C_{T}\right) \\
\frac{\partial}{\partial t}{ }^{13} C_{T}=-\nabla \cdot\left(\mathbf{u}{ }^{13} C_{T}-K \cdot \nabla{ }^{13} C_{T}\right)+q_{v}\left({ }^{13} C_{T}\right) \\
\frac{\partial}{\partial t}{ }^{14} C_{T}=-\nabla \cdot\left(\mathbf{u}{ }^{14} C_{T}-K \cdot \nabla{ }^{14} C_{T}\right)+q_{v}\left({ }^{14} C_{T}\right)-\lambda^{14} C_{T}
\end{gathered}
$$

with $\lambda$ the decay rate for ${ }^{14} \mathrm{C}$. The term $\mathrm{q}_{\mathrm{v}}(\mathrm{X})$ represents appropriate source minus sink term for tracer $\mathrm{X}$. It takes into account biotic or abiotic (e.g. $\mathrm{CaCO}_{3}$ dissolution) processes, at the exclusion of radioactive decay.

At the ocean-atmosphere interface, we impose a Neumann boundary condition. With $\mathfrak{I}$ the carbon flux through the air-sea interface, the boundary condition for $\mathrm{C}_{\mathrm{T}}$ reads

$$
\mathrm{n} \cdot\left(\mathrm{K} \cdot \nabla \mathrm{C}_{\mathrm{T}}\right)=\mathfrak{I}=\mathrm{F}^{\text {as }}-\mathrm{F}^{\mathrm{sa}}
$$

where $\mathrm{n}$ is a unit vector normal to the interface. The individual flux components are given by

$$
\mathrm{F}^{\mathrm{as}}=\kappa_{\mathrm{CO} 2} \mathrm{~K}_{\mathrm{H}} \mathrm{p}^{\mathrm{a}} \mathrm{CO} 2 \text { and } \mathrm{F}^{\mathrm{sa}}=\kappa_{\mathrm{CO} 2} \mathrm{CO}_{2 \mathrm{~s}}
$$

where the superscripts $a s$ and $s a$ refer to the air-to-sea and sea-to-air transfers, respectively. In (7), $\kappa_{\mathrm{CO} 2}$ is the carbon dioxide transfer velocity, $\mathrm{K}_{\mathrm{H}}$ the $\mathrm{CO}_{2}$ solubility in seawater, $\mathrm{p}_{\mathrm{CO} 2}^{\mathrm{a}}$ the atmospheric pressure at sea level, and $\mathrm{CO}_{2 \mathrm{~s}}$ the concentration of dissolved carbon dioxide in seawater, which is obtained by computing carbonate speciation.

The air-sea boundary conditions for isotopes are based on (6) and (7) with fractionation factors and isotopic ratios weighting the different fluxes (Heimann and Maier-Reimer 1996). These fluxes read

$$
\begin{aligned}
& { }^{13} \mathfrak{I}={ }^{13} \alpha{ }^{a s 13} R_{a} F^{a s}-{ }^{13} \alpha{ }^{s a 13} R_{C_{T}} F^{s a} \\
& { }^{14} \mathfrak{I}={ }^{14} \alpha{ }^{a s 14} R_{a} F^{a s}-{ }^{14} \alpha{ }^{s a 14} R_{C_{T}} F^{s a}
\end{aligned}
$$




\section{A Mouchet}

Here, ${ }^{i} R_{a}$ and ${ }^{i} R_{C_{T}}$ represent isotopic ratios (i $=13$ or 14) in atmospheric $\mathrm{CO}_{2}$ and in ocean DIC, respectively. Fractionation effects between atmospheric and dissolved carbon dioxide are represented by ${ }^{13} \alpha^{a s}$ while ${ }^{13} \alpha^{s a}$ contains the fractionation factors between dissolved $\mathrm{CO}_{2}$ and carbonate species.

The equations (3)-(5) together with the boundary conditions (6)-(9) and appropriate expressions for the source and sink terms constitute the complete set of equations of use in ${ }^{14} \mathrm{C}$ modeling. In the following, we refer to this calculation as the F method.

\section{A Simplified Formulation}

Since $\Delta^{14} \mathrm{C}$ represents the ratio that would have been observed if isotopic fractionation did not occur, it may be used as such as a physical tracer of ocean ventilation (Broecker et al. 1961; Maier-Reimer 1993). Hence, as was initially suggested by Toggweiler et al. (1989a,b), in many model studies the ratio ${ }^{14} \mathrm{R}$ is transported rather than the individual concentrations. By combining the transport equations (3) and (5), one obtains the equation governing the evolution of the ratio ${ }^{94} R_{C_{T}}$

$$
\frac{\partial}{\partial t}{ }^{14} R_{C_{T}}=-\nabla \cdot\left(u^{14} R_{C_{T}}-K \cdot \nabla^{14} R_{C_{T}}\right)+\frac{1}{C_{T}}\left(q_{v}\left({ }^{14} C\right)-{ }^{14} R_{C_{T}} q_{v}\left(C_{T}\right)\right)-\lambda{ }^{14} R_{C_{T}}+\frac{2}{C_{T}} \nabla C_{T} \cdot K \cdot \nabla{ }^{14} R_{C_{T}}(10)
$$

The last term on the right-hand side is generated by mixing processes and has no equivalent in the equation governing concentrations. This term may, in most parts of the deep ocean, be considered as a sink term. Indeed, the oldest ocean water (lowest ${ }^{14} \mathrm{R}$ ) would generally correspond to those with the highest $\mathrm{C}_{\mathrm{T}}$ content.

Solving Equation 10 would call for a specific numerical scheme, different from the one applied to the other variables in the model (temperature, salinity, tracers...) with consequences that ${ }^{14} \mathrm{R}$ would loose its relevance for diagnosing the model circulation and ventilation timescale. Therefore, in order to represent the ratio ${ }^{14} \mathrm{R}$ in the numerical model, the mixed product in Equation 10 must vanish. It is equivalent to assuming that the $\mathrm{C}_{\mathrm{T}}$ field is homogeneous and constant, i.e.

$$
\mathrm{C}_{\mathrm{T}}(\mathrm{x}, \mathrm{t})=\overline{C_{T}}
$$

with $\overline{C_{T}}$ a typical DIC concentration and $\mathrm{x}$ the position. Further, since ${ }^{14} \mathrm{R}$ is considered as a purely physical tracer, biological activity and fractionation factors are ignored. Under these hypotheses, (10) becomes

$$
\frac{\partial}{\partial t}{ }^{14} R_{C_{T}}=-\nabla \cdot\left(u^{14} R_{C_{T}}-K \cdot \nabla^{14} R_{C_{T}}\right)-\lambda^{14} R_{C_{T}}
$$

Denoting ${ }^{\mathrm{R}} \mathfrak{I}$ the flux of ${ }^{14} \mathrm{R}$ through the air-sea interface, the boundary condition to be applied to (12) is

$$
n \cdot\left(K \cdot \nabla^{14} R_{C_{T}}\right)={ }^{R_{\mathfrak{J}}}
$$

This condition may be expressed in terms of the boundary conditions for $\mathrm{C}_{\mathrm{T}}$ and ${ }^{14} \mathrm{C}$. Indeed, with the help of Equations 6, 7, and 9 in which we neglect fractionation, (13) becomes:

$$
R_{\mathfrak{I}}=n \cdot\left(K \cdot \nabla^{14} R_{C_{T}}\right)=n \cdot\left(K \cdot\left(\frac{\nabla^{14} C_{T}}{C_{T}}-{ }^{14} R_{C_{T}} \frac{\nabla C_{T}}{C_{T}}\right)\right)
$$




$$
\begin{gathered}
=\frac{1}{C_{T}}\left({ }^{14} \mathfrak{I}-{ }^{14} R_{C_{T}} \mathfrak{I}\right) \\
=\frac{1}{C_{T}}\left[\left({ }^{14} R_{a} F^{a s}-{ }^{14} R_{C_{T}} F^{s a}\right)-{ }^{14} R_{C_{T}}\left(F^{a s}-F^{s a}\right)\right]
\end{gathered}
$$

Then, with assumption (11) the flux ${ }^{\mathrm{R}} \mathfrak{I}$ reads

$$
{ }^{R_{\mathfrak{I}}}=\frac{{ }_{\mathrm{KO}_{2}} K_{H}}{\overline{C_{T}}} p_{\mathrm{CO}_{2}}^{a}\left({ }^{14} R_{a}-{ }^{14} R_{C_{T}}\right)
$$

The implications of Equation 15 may be understood by comparing it to (9) which, with the help of (7) and ignoring the minor effect of fractionation, reads

$$
\begin{gathered}
{ }^{14} \mathfrak{J}=\kappa_{\mathrm{CO}_{2}}\left({ }^{14} R_{a} K_{\mathrm{H}} p_{\mathrm{CO}_{2}}^{a}-{ }^{14} R_{C_{T}} \mathrm{CO}_{2 s}\right)=\kappa_{\mathrm{CO}_{2}} K_{H}\left({ }^{14} R_{a} p_{C O_{2}}^{a}-{ }^{14} R_{C_{T}} p_{\mathrm{CO}_{2}}^{s}\right) \\
=\kappa_{\mathrm{CO}_{2}} K_{\mathrm{H}}\left(p_{\mathrm{CO}}^{a}\left({ }^{a} R_{a}-{ }^{14} R_{C_{T}}\right)+\left(p_{C O_{2}}^{a}-p_{\mathrm{CO}_{2}}^{s}\right){ }^{14} R_{C_{T}}\right)
\end{gathered}
$$

where $p_{\mathrm{CO}_{2}}^{s}$ is the partial pressure of $\mathrm{CO}_{2}$ in the ocean. The second term on the right-hand side of (16) represents the contribution of air-sea $\mathrm{CO}_{2}$ disequilibrium to the ${ }^{14} \mathrm{C}$ flux. Since this term does not intervene in the computation of ${ }^{\mathrm{R}} \mathfrak{I}$, the form (15) is equivalent to assuming local air-sea $\mathrm{CO}_{2}$ equilibrium. It means that any method based on (15) postulates that the ${ }^{14} \mathrm{C}$ fluxes into the ocean have a time history directly proportional to the atmospheric ${ }^{14} \mathrm{C}$ perturbation and ignores the role of air-sea $\mathrm{CO}_{2}$ flux in setting the ${ }^{14} \mathrm{C}$ exchange rate. The method represented by the set of Equations 12 and 15 will hereafter be referred to as the $\mathrm{R}$ method.

\section{Model Setup}

We use the ocean carbon cycle model LOCH (Mouchet and François 1996; Menviel et al. 2008; Goosse et al. 2010) in its abiotic version to simulate ocean carbon chemistry. We restrict the present discussion to abiotic processes since it may be shown that the impact of biological activity on the global figures discussed here is negligible (Müller et al. 2008; Mouchet 2011). LOCH is driven offline by three-dimensional fields of velocity components, potential temperature, salinity, and convective mixing from 2 OGCMs in their annually averaged versions: the Large-Scale Geostrophic Ocean General Circulation Model (LSG-OM; Maier-Reimer et al. 1993; Mikolajewicz et al. 1993) and the Louvain-la-Neuve OGCM (UL-OM; Deleersnijder and Campin 1995; Campin and Goosse 1999). These models belong to the coarse-grid OGCM class but nevertheless capture the key features of ocean circulation. The use of both circulation fields is motivated by the differences they exhibit in the processes controlling the distribution of tracers and in the circulation characteristic scales (Mouchet et al. 2012). Diffusion in UL-OM is mostly explicit with maxima in the upper layers and in convective areas. This is in contrast to LSG-OM in which numerical diffusion (a more ubiquitous process) prevails in setting the effective diffusivity. For a discussion of these processes and more details on the OGCMs used in this study, see Mouchet et al. (2012) and references therein.

The gas transfer velocity is based on the empirical formulation of Wanninkhof (1992). We consider a reduced air-sea exchange rate in the presence of sea ice. Therefore, the piston velocity in the model is computed in the following way

$$
\kappa_{\mathrm{CO}_{2}}=\left(1-f_{\text {ice }}\right) K_{W^{w^{2}}} \sqrt{660 / S c}
$$




\section{A Mouchet}

with $f_{\text {ice }}$ the fraction of the sea surface covered with ice and $S c$ the Schmidt number. The long-term average of the squared wind magnitude $\overline{w^{2}}$ is taken from the annual climatology of Trenberth et al. (1989). The annual average of sea-ice fraction is computed with the help of the OCMIP-2 sea-ice cover climatology (Orr et al. 2000). Both wind and sea ice fields were carefully interpolated onto both OGCM grids to reduce the differences between carbon cycle experiments to a strict minimum.

The Schmidt number $S c$ is calculated with the help of the formulation of Wanninkhof (1992). The $\mathrm{CO}_{2}$ solubility (taken from Weiss 1974 ) as well as $S c$ are computed with the OGCM temperature and salinity fields. The coefficient $K_{W}$ in (17) is then adjusted to obtain an average value of the $\mathrm{CO}_{2}$ invasion rate (i.e. $\kappa_{\mathrm{CO} 2} \times$ solubility) of the order of $0.061 \mathrm{~mol} \mathrm{ppm}^{-1} \mathrm{~m}^{-2} \mathrm{yr}^{-1}$ with an atmospheric $\mathrm{CO}_{2}$ of $280 \mathrm{ppm}$ (Siegenthaler 1986; Watson and Liss 1998). In the reference experiments, the globally averaged $\mathrm{CO}_{2}$ piston velocity is $17.2 \mathrm{~cm} / \mathrm{hr}$ with LSG-OM and $17.1 \mathrm{~cm} / \mathrm{hr}$ with UL-OM.

The temperature-dependent formulations for the fractionation factors in (8) are from Vogel et al. (1970) and Mook et al. (1974), and the small kinetic effect on gas exchange velocities is taken from Siegenthaler and Münnich (1981). Fractionation factors for ${ }^{14} \mathrm{C}$ are the squares of those for ${ }^{13} \mathrm{C}$ (Siegenthaler and Münnich 1981). Since the model considers the full carbonate chemistry and since individual fractionation factors are applied between the different dissolved carbonate species, the total fractionation occurring during air-sea exchange also depends on $\mathrm{CO}_{2}$ concentration.

We performed experiments over the industrial era in which the ocean ${ }^{14} \mathrm{C}$ distribution is computed according to the $\mathrm{F}$ or $\mathrm{R}$ method. In addition, 2 experiments address the sensitivity of bomb ${ }^{14} \mathrm{C}$ inventories to the transfer velocity; in these $K_{W}$ is increased by $10 \%$ and decreased by $\sim 15 \%$, respectively. Each of the ${ }^{14} \mathrm{C}$ modeling methods ( $\mathrm{F}$ or $\mathrm{R}$ ) requires its own initial conditions. This rule also prevails for experiments addressing the sensitivity to piston velocity. In total, 4 pre-industrial states were prepared with each circulation fields in order to provide the initial conditions to the corresponding transient experiments (Table 1). The $\Delta^{14} \mathrm{C}$ values in the ocean are initialized to a globally uniform pre-bomb value of $-140 \%$. The model is then run to equilibrium constrained by pre-industrial atmospheric values of $\mathrm{CO}_{2}, \delta^{13} \mathrm{C}$, and $\Delta^{14} \mathrm{C}(277.95 \mathrm{ppm},-6.51 \%$, and $0 \%$, respectively). For the value of $\overline{C_{T}}$ intervening in Equation 15, we use the globally averaged surface $\mathrm{C}_{\mathrm{T}}$ concentration obtained from the equilibrium experiment $\mathrm{F} 0$. To simulate ocean ${ }^{14} \mathrm{C}$ during the industrial era, we force atmospheric $\mathrm{CO}_{2}, \delta^{13} \mathrm{C}$, and $\Delta^{14} \mathrm{C}$ to follow the historical estimates. $\mathrm{CO}_{2}$ and $\Delta^{14} \mathrm{C}$ are from Enting et al. (1994) and OCMIP-2 (Orr et al. 2000) while $\delta^{13} \mathrm{C}$ data are from Francey et al. (1999) up to 1978 and from Keeling et al. (2010) onward. Two additional experiments are performed in which the atmospheric $\mathrm{CO}_{2}$ (and consequently ${ }^{13} \mathrm{R}$ ) is maintained at its pre-industrial level. The purpose of these additional experiments is to illustrate the role of the anthropogenic $\mathrm{CO}_{2}$ increase in the bomb ${ }^{14} \mathrm{C}$ ocean uptake. Transient experiments are identified this way: the first letter refers to the ${ }^{14} \mathrm{C}$ modeling method ( $\mathrm{R}$ or $\mathrm{F}$ ), the second letter to the type of $\mathrm{CO}_{2}$ forcing over the industrial era (C: $\mathrm{CO}_{2}$ maintained at pre-industrial value, or $\mathrm{P}: \mathrm{CO}_{2}$ from the historical record), and the third letter, when present, to the magnitude of $\kappa \mathrm{CO}_{2}(\mathrm{~L}$ or $\mathrm{H}$, respectively) with respect to the reference state. Hence, 6 transient experiments were carried on with each circulation fields. They are summarized in Table 1. Except for FC, each one of these methods has its equivalent in the literature. The analysis of Joos et al. (1997) and Müller et al. (2008) are performed in a similar way as FP. The F method with biological cycle is considered in the works of Bacastow and Maier-Reimer (1990) and Heimann and Maier-Reimer (1996). The transient experiments of Toggweiler et al. (1989b), Rodgers et al. (2000), Mahadevan (2001), and Ito et al. (2004) are identical to those that we call RC. The ${ }^{14} \mathrm{C}$ experiments during OCMIP-1 (Orr et al. 2001) and in Müller et al. (2006) are based on the RP protocol. In addition, Krakauer et al. (2006) and Sweeney et al. (2007) rely at some stage for their field estimates on model experiments performed the same way as RP. 
Table 1 Summary of the modeling experiments setup. Experiment name and method are given in columns 1 and 2, with the initial condition (IC) for transient experiments in column 3. Column 4 contains the multiplicative factor of the reference $\mathrm{CO}_{2}$ transfer velocity. Columns 5 to 7 display the atmospheric forcing (pre-industrial PI or industrial I) for $\mathrm{CO}_{2}, \delta^{13} \mathrm{C}$, and $\Delta{ }^{14} \mathrm{C}$, respectively.

\begin{tabular}{lllllll}
\hline Name & Method & $\mathrm{IC}$ & $\times \kappa_{\mathrm{CO} 2}$ & $p_{C O_{2}}^{a}$ & ${ }^{13} \mathrm{R}_{a}$ & ${ }^{14} \mathrm{R}_{a}$ \\
\hline R0 & R & - & 1 & PI & - & PI \\
F0 & F & - & 1 & PI & PI & PI \\
F0L & F & - & 0.85 & PI & PI & PI \\
F0H & F & - & 1.10 & PI & PI & PI \\
RC & R & R0 & 1 & PI & - & I \\
RP & R & R0 & 1 & I & - & I \\
FC & F & F0 & 1 & PI & PI & I \\
FP & F & F0 & 1 & I & I & I \\
FPL & F & F0L & 0.85 & I & I & I \\
FPH & F & F0H & 1.10 & I & I & I \\
\hline
\end{tabular}

\section{RESULTS}

\section{Pre-Industrial State}

As illustrated in Figure 1, there is a fair agreement between model results in the upper ocean and the "natural" or pre-bomb $\Delta^{14} \mathrm{C}$ distribution as reconstructed by Key et al. (2004). The contrast between the Southern Ocean and the other ocean basins is reasonably reproduced despite less-negative $\Delta^{14} \mathrm{C}$ values in the upper ocean predicted by the models with respect to the GLODAP reconstruction. Some of this discrepancy could result from the Suess effect, which decreased surface ocean $\Delta^{14} \mathrm{C}$ by 6 to $12 \%$ from 1900 to 1952 (Druffel and Suess 1983). The data-based reconstruction meant to be representative of the pre-bomb state (i.e. the early 1950s; Rubin and Key 2002) might indeed be affected to some extent by this process, which is not present in the modeled pre-industrial states. However, model shortcomings cannot be ruled out. Profiles in the deep Atlantic Ocean agree reasonably with data, but both models fail to reproduce deep $\Delta^{14} \mathrm{C}$ in the Southern and Pacific Oceans. One may not invoke the neglect of biological processes to explain such departures. Biological activity actually contributes to the ${ }^{14} \mathrm{C}$ pool at depth (Craig 1969), but its impact is nearly totally eliminated by the use of fractionation-corrected ${ }^{14} \mathrm{R}$ (Stuiver et al. 1981; Bacastow and Maier-Reimer 1990; Maier-Reimer 1993; Joos et al. 1997). The main reasons for such discrepancies between model and data are probably to be found in the representation of convective events and vertical mixing processes in coarse grid OGCMs, which generally do not simulate the deep natural ${ }^{14} \mathrm{C}$ distribution well (e.g. Orr et al. 2001; Matsumoto et al. 2004). However, this shortcoming does not necessarily affect processes characterized by short timescales, such as the one at stake.

Pre-industrial or equilibrium $\Delta^{14} \mathrm{C}$ distributions do not differ much among the different configurations. The close correspondence of R0 and F0 profiles implies that the contribution of the mixed product term in (10) is very small. The R0 and F0 profiles in the North Atlantic depart more from each other in the LSG-OM case than in the UL-OM case. This is due to the representation of freshwater fluxes in the OGCMs. In LSG-OM, these fluxes are treated as water fluxes and incorporated in the velocity field divergence. In experiments F0, these fluxes affect the individual tracers and mostly cancel out when ratios are computed. In experiments with the $\mathrm{R}$ method, these implicit fluxes directly affect the ${ }^{14} \mathrm{R}$ ratio. Evaporation is comparatively high in the North Atlantic Ocean, which leads to increased concentrations in that area. This problem is not present with the UL-OM fields since evaporation and precipitation are represented by means of an explicit flux condition at the 


\section{A Mouchet}

ocean surface. When performing R experiments with UL-OM, we set these fluxes to zero. We did not attempt to correct for these fluxes in experiments performed with LSG-OM and addressing the $\mathrm{R}$ method. Indeed, the results presented hereafter suggest that the influence of these fluxes on estimated inventories is very small with respect to other factors elaborated below.
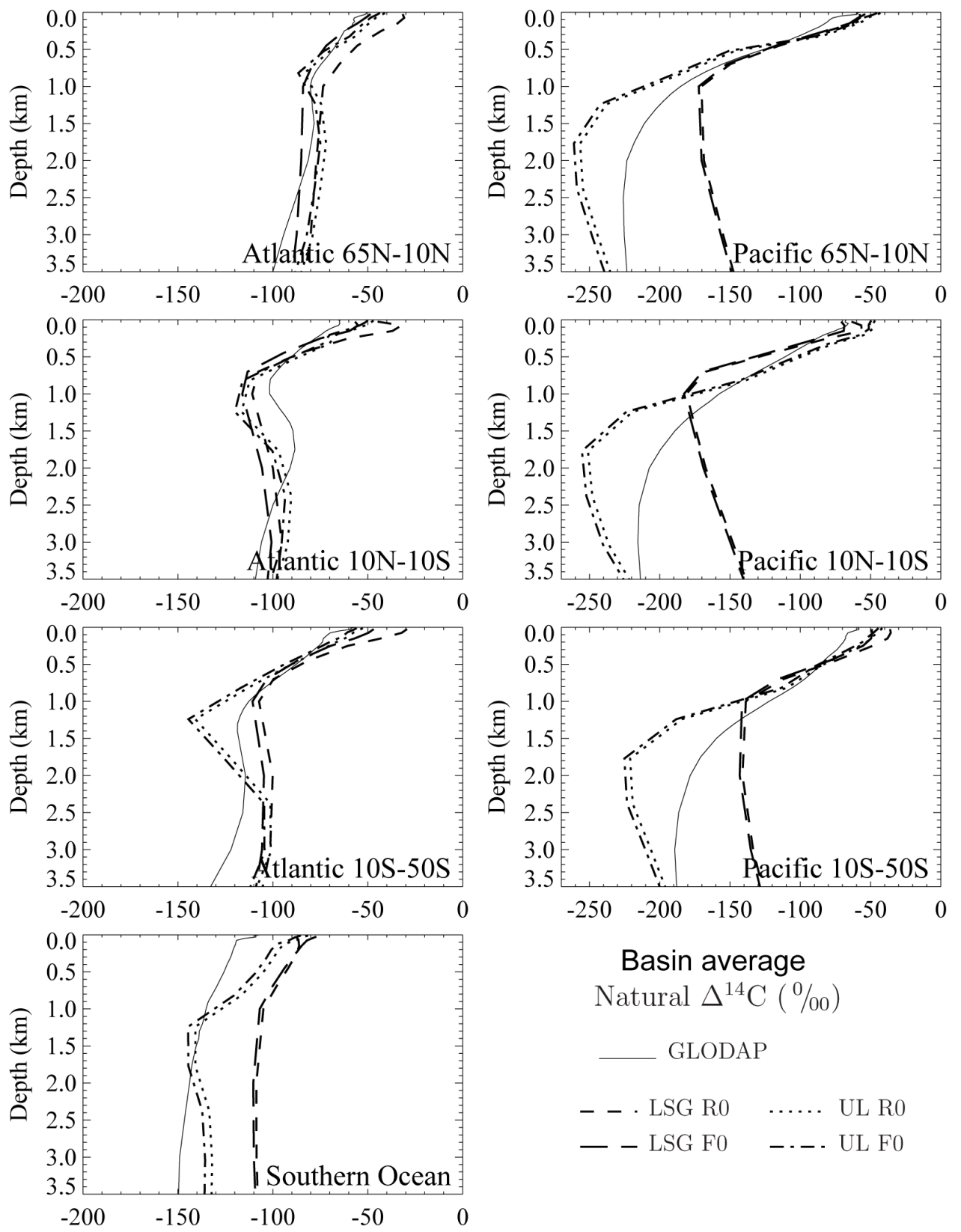

\section{Basin average}

Natural $\Delta^{14} \mathrm{C}(\%)$

\section{GLODAP}

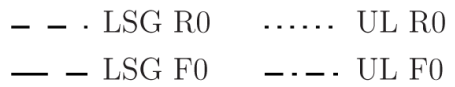

Figure 1 Mean natural $\Delta^{14} \mathrm{C}$ vertical profiles in several ocean basins from the GLODAP reconstruction (solid lines; Key et al. 2004) and from experiments F0 and R0 with circulation fields from LSG-OM (LSG) and UL-OM (UL) OGCMs. The values in the north, equatorial, and southern Atlantic and Pacific oceans are reproduced, respectively, in the upper left and right 3 panels, with the bottom panel representing the Southern Ocean (south of $50^{\circ} \mathrm{S}$ ). 


\section{The Ocean Bomb ${ }^{14}$ C Inventory Revisited}

\section{Response to Anthropogenic Forcing}

The global net $\mathrm{CO}_{2}$ fluxes into the ocean during the $1980 \mathrm{~s}$ and the $1900 \mathrm{~s}$ amount to $1.86 \mathrm{GtC} / \mathrm{yr}$ and $2.15 \mathrm{GtC} / \mathrm{yr}$, respectively, for experiment FP with both circulation fields (Table 2). These values are within the range of estimates based on observations and model studies (Matsumoto et al. 2004; Gruber et al. 2009). The inventory of anthropogenic carbon in the ocean predicted with both circulation fields ( ${ }^{C} I_{1800}^{1994}$ in Table 2$)$ is also in good agreement with inventories based on observations (118 \pm 19 PgC; Sabine et al. 2004).

Table 2 Simulated ocean bomb ${ }^{14} \mathrm{C}$ inventories and ocean $\mathrm{CO}_{2}$ uptake. ${ }^{14} I_{1940}^{1975}$ and ${ }^{14} I_{1940}^{1990}$ are the ${ }^{14} \mathrm{C}$ inventories (in $10^{26}$ at.) relative to 1940 for 1975 and 1990 , respectively. ${ }^{14} I_{1975}^{1990}$ is the net bomb ${ }^{14} \mathrm{C}$ uptake from 1975 to 1990 (i.e. the difference between the 2 former inventories). $\mathfrak{J}_{1980 s}$ and $\mathfrak{J}_{1990 s}$ correspond to the $\mathrm{CO}_{2}$ uptake rates $(\mathrm{GtC} / \mathrm{yr})$ during the $1980 \mathrm{~s}$ and $1990 \mathrm{~s}$, respectively. The last line contains ${ }^{C} I_{1800}^{1994}$, the cumulative ocean $\mathrm{CO}_{2}$ uptake (GtC) over the period $1800-1994$.

\begin{tabular}{|c|c|c|c|c|c|c|c|c|c|c|c|c|}
\hline \multicolumn{7}{|c|}{ UL-OM } & \multicolumn{6}{|c|}{ LSG-OM } \\
\hline & $\mathrm{RC}$ & $\mathrm{RP}$ & FC & FP & FPL & FPH & $\mathrm{RC}$ & $\mathrm{RP}$ & $\mathrm{FC}$ & FP & FPL & FPH \\
\hline${ }^{14} I_{1940}^{1975}$ & 239 & 272 & 236 & 288 & 257 & 306 & 244 & 277 & 241 & 294 & 262 & 312 \\
\hline${ }^{14} I_{1940}^{1990}$ & 313 & 355 & 309 & 388 & 352 & 407 & 322 & 365 & 318 & 399 & 361 & 418 \\
\hline${ }^{14} I_{1975}^{1990}$ & 74 & 83 & 73 & 100 & 95 & 101 & 78 & 88 & 77 & 105 & 99 & 106 \\
\hline$\widetilde{\mathfrak{I}}_{1980 \mathrm{~s}}$ & - & - & - & 1.86 & 1.81 & 1.89 & - & - & - & 1.86 & 1.82 & 1.88 \\
\hline $\mathfrak{I} 1990 \mathrm{~s}$ & - & - & - & 2.15 & 2.10 & 2.18 & - & - & - & 2.15 & 2.11 & 2.17 \\
\hline${ }^{C} I_{1800}^{1994}$ & - & - & - & 116 & 119 & 121 & - & - & - & 119 & 121 & 122 \\
\hline
\end{tabular}

The simulated post-bomb $\Delta{ }^{14} \mathrm{C}$ ocean distribution is illustrated in Figure 2 . The ${ }^{14} \mathrm{C}$ increase is reasonably well captured by the model. Bomb ${ }^{14} \mathrm{C}$ inventories with UL-OM and with LSG-OM are similar (Table 2), with the latter predicting slightly larger values. On the other hand, the spread among results with different ${ }^{14} \mathrm{C}$ modeling methods is much larger than the differences related to circulation fields. Experiments FC and RC predict similarly low inventories. Larger inventories are obtained with RP experiments while FP predicts the largest uptake.

The low $\mathrm{RC}$ and $\mathrm{FC}$ inventories are a direct consequence of neglecting the $\mathrm{CO}_{2}$ increase over the industrial era. Lower $\mathrm{CO}_{2}$ levels imply lower amounts of ${ }^{14} \mathrm{C}$ atoms for an identical $\Delta{ }^{14} \mathrm{C}$. The small difference between $\mathrm{FC}$ and $\mathrm{RC}$ inventories is to be attributed to the respective treatment of air-sea $\mathrm{CO}_{2}$ fluxes. Indeed, formulation $\mathrm{RC}$ assumes no net air-sea $\mathrm{CO}_{2}$ exchange at the local scale while in experiments FC these fluxes are globally, not locally, balanced. The net global $\mathrm{CO}_{2}$ flux is zero in both cases, but spatial variability in $\mathrm{FC}$ slightly affects the global ${ }^{14} \mathrm{C}$ invasion rates. Experiments $\mathrm{RP}$ take into account the atmospheric $\mathrm{CO}_{2}$ increase but still lag behind experiments FP. As mentioned when introducing the method consisting in transporting the ${ }^{14} \mathrm{R}$ ratio, this method implicitly assumes that air-sea $\mathrm{CO}_{2}$ equilibrium prevails. The last term on the right-hand side of (16) fully explains the differences between the RP and FP inventories. In the eventuality of constant atmospheric ${ }^{14} \mathrm{R}$, this term would still drive a net ${ }^{14} \mathrm{C}$ uptake by the ocean under increasing atmospheric $\mathrm{CO}_{2}$. Not only does the atmospheric $\mathrm{CO}_{2}$ perturbation increases exponentially after 1940 , but due to the limited rate of the $\mathrm{CO}_{2}$ exchange between the atmosphere and the ocean (typically 1 yr for a 50m-deep column; Broecker and Peng 1974; Lynch-Stieglitz et al. 1995) and to the permanent renewal of surface waters, the ocean dissolved $\mathrm{CO}_{2}$ increases less rapidly than atmospheric $\mathrm{CO}_{2}$. Enhanced air-to-sea $\mathrm{CO}_{2}$ fluxes drive a larger ${ }^{14} \mathrm{C}$ flux to the ocean in experiments $\mathrm{FP}$ than in experiments $\mathrm{RP}$. 


\section{A Mouchet}
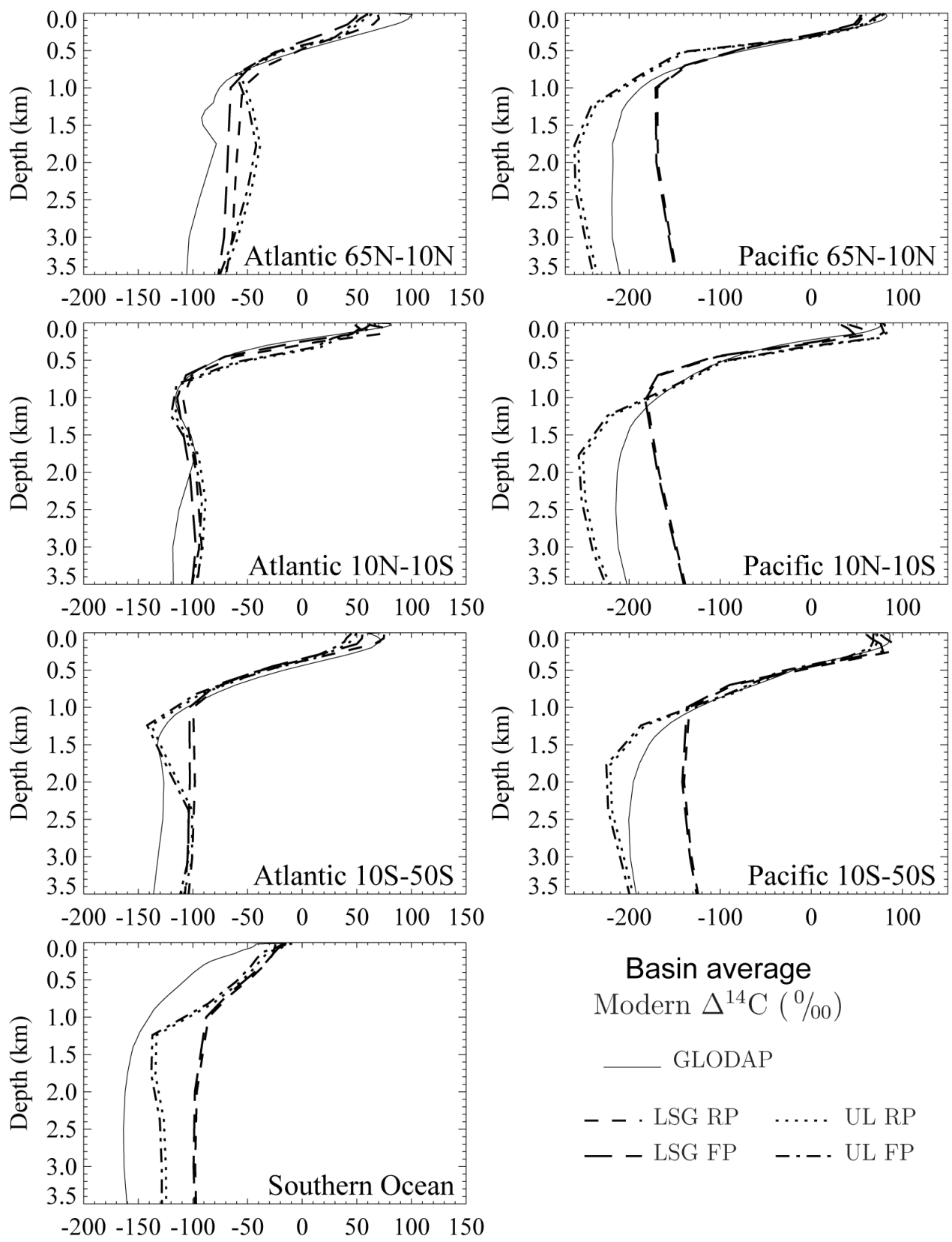

Figure 2 Mean $\Delta^{14} \mathrm{C}$ vertical profiles in several ocean basins from GLODAP (solid lines; Key et al. 2004) and from experiments FP and RP with circulation fields from LSG-OM (LSG) and UL-OM (UL) OGCMs. The values in the north, equatorial, and southern Atlantic and Pacific oceans are reproduced, respectively, in the upper left and right 3 panels, with the bottom panel representing the Southern Ocean (south of $50^{\circ} \mathrm{S}$ ). Model values correspond to the year 2000.

The numerical experiments allow to quantify the relative role of each process in the build up of the simulated ocean bomb ${ }^{14} \mathrm{C}$ inventories relative to $1940 .{ }^{14} I_{1940}^{1990}$ results from 3 contributions: the atmospheric $\Delta^{14} \mathrm{C}$ increase consecutive to the nuclear tests (exp. FC or RC) explains $80 \%$ of the FP 
inventory, the anthropogenic $\mathrm{CO}_{2}$ increase (RP minus $\mathrm{RC}$ ) contributes by $11 \%$ and the remaining $9 \%$ results from the enhanced air-sea $\mathrm{CO}_{2}$ disequilibrium (FP minus RP). The contribution of the last process to the final inventory is significant; indeed, it is of the same order of magnitude as the second one. Inventory anomalies in 1990 with respect to 1975 follow the same pattern as the gross inventories $\left({ }^{14} I_{1975}^{1990}\right.$ in Table 2). However, they exhibit larger relative differences yet. For FC and RC, ${ }^{14} I_{1975}^{1990}$ amounts only to $73-74 \%$ of the value obtained with FP, while ${ }^{14} I_{1975}^{1990}$ for RP represents $83-84 \%$ that of FP. It implies that over the timeframe of relevant observations (i.e. from GEOSECS to WOCE), the bomb ${ }^{14} \mathrm{C}$ inventory is extremely sensitive to the method used for computing it. Table 2 also contains the inventories obtained with a 15\% lower (FPL) and a $10 \%$ larger (FPH) gas exchange velocity. The bomb ${ }^{14} \mathrm{C}$ inventory in 1990 changes by $\sim 15 \%$ and the net $\mathrm{CO}_{2}$ flux by $\sim 4 \%$ over the velocity range considered here. Indeed, air-sea exchange rate exerts a dominant control on ocean ${ }^{14} \mathrm{C}$ uptake in contrast to the $\mathrm{CO}_{2}$ uptake whose rate limiting process is the renewal time of ocean surface water with lesser control by the piston velocity (Broecker and Peng 1974; LynchStieglitz et al. 1995; Ito et al. 2004).

\section{DISCUSSION AND CONCLUSIONS}

Previous works addressing the ocean bomb ${ }^{14} \mathrm{C}$ inventory with numerical models made use of different formulations of the ${ }^{14} \mathrm{C}$ isotopic ratio. Three representations are identified that yield distinct air-sea ${ }^{14} \mathrm{C}$ flux rates. In the first (method RC), the air-to-sea ${ }^{14} \mathrm{C}$ flux is simply proportional to the atmospheric $\Delta^{14} \mathrm{C}$ signal. With the second (method RP), the actual atmospheric $\mathrm{CO}_{2}$ concentration weights the ${ }^{14} \mathrm{C}$ flux. Eventually, with the third method (FP), which necessitates a comprehensive carbon cycle model, the $\mathrm{CO}_{2}$ uptake by the ocean is also considered. With respect to inventories, the 3 methods lead to a larger range of results than those obtained with the circulation of 2 different OGCMs.

Inventories based on observations, on the other hand, rely on similar assumptions as method R, i.e. that DIC concentrations remain constant with time (Broecker et al. 1995; Key et al. 2004; Naegler 2009). Since reconstructed natural $\Delta^{14} \mathrm{C}$ is constrained to match the pre-bomb observations (Rubin and Key 2002; Sweeney et al. 2007), these inventories nevertheless provide an estimate of the actual ocean $\Delta^{14} \mathrm{C}$ increase. Therefore, data-based inventories are expected to yield similar results as method RP.

Figure 3 displays our results together with estimates from the literature. Method RC, by underestimating the ocean $\Delta^{14} \mathrm{C}$ increase over the post-bomb times, predicts the lowest inventories. This is probably the explanation for the low estimates obtained with some previous model studies (e.g. Duffy and Caldeira 1995). The spread among model results arises from different strategies for calibrating mixing parameters and air-sea gas exchange coefficient in ocean models. The model of Joos and Bruno (1998) was tuned against the GEOSECS data, while Müller et al. (2008) optimized their model through a multi-tracer approach, in which the RP method is of use for constraining bomb ${ }^{14} \mathrm{C}$ toward the Key et al. (2004) inventory (Müller et al. 2006). Both studies afterwards applied the FP formulation in their assessment of the bomb ${ }^{14} \mathrm{C}$ inventory. In contrast to these works, I did not calibrate any of the model parameters with the help of ${ }^{14} \mathrm{C}$ data.

In order to be compared to OGCM results, inventories based on observations have to be corrected for insufficient spatial coverage as well as for lack of measurement synchronization (Naegler et al. 2006; Sweeney et al. 2007; Naegler 2009). The N06 value in Figure 3 represents the Key et al. (2004) inventory corrected for such biases (Naegler et al. 2006). The Peacock (2004) inventory also needs to be revised upward for missing ocean areas (Naegler et al. 2006). Eventually, according to Sweeney et al. (2007) their 1975 inventory may be biased low by as much as $10 \%$. Considering 


\section{A Mouchet}

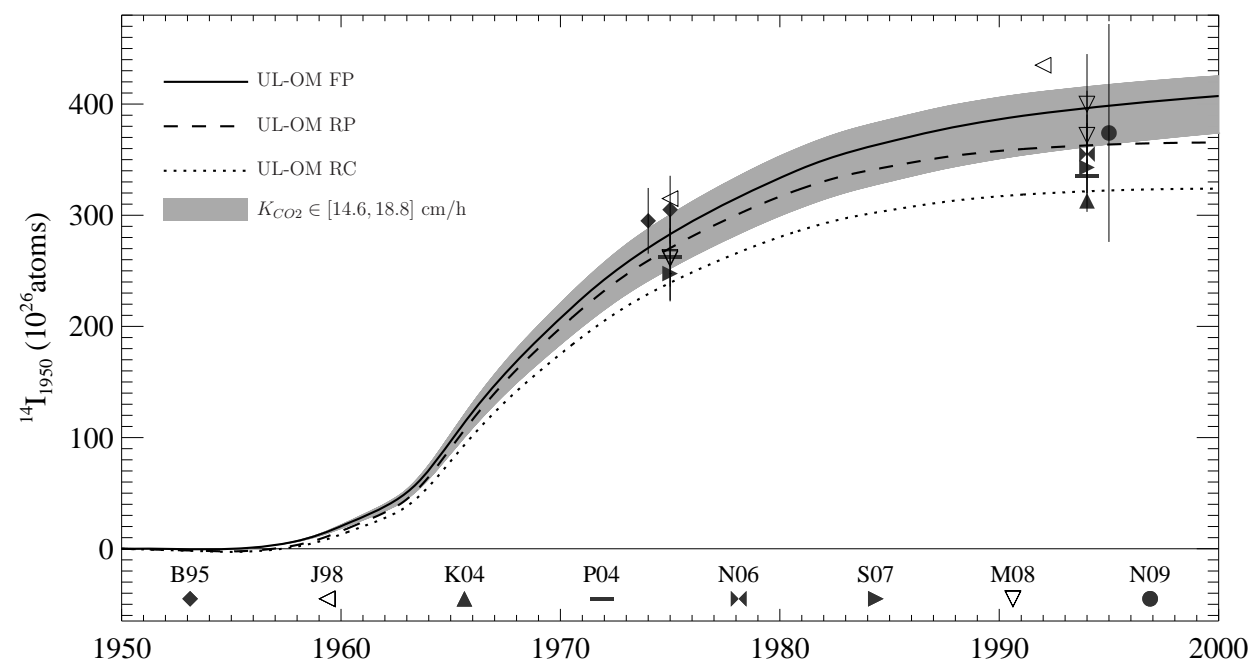

Figure 3 Ocean bomb ${ }^{14} \mathrm{C}$ inventory relative to 1950 for experiments $\mathrm{FP}, \mathrm{RP}$, and RC with UL-OM (identical curves are obtained with LSG-OM). Upper and lower bounds of the gray area correspond to experiments FPH and FPL. Estimates from the literature are also illustrated. Data (filled symbol) and model (open symbol) values as originally published by Broecker et al. (1995) B95, Joos and Bruno (1998) J98, Key et al. (2004) K04, Peacock (2004) P04, Naegler et al. (2006) N06, Sweeney et al. (2007) S07, Müller et al. (2008) M08, and Naegler (2009) N09. Where available, error bars (B95, P04, and N09) or model result range (M08) are also shown.

these facts, there is a fair agreement between the RP-modeled and data-based inventories, with the exception of the values from Broecker et al. (1995), which are probably biased high (Peacock 2004; Naegler et al. 2006).

Two important facts emerge from Figure 3. First, inventories reconstructed from field observations for which the RP predicted values are the model equivalent, underestimate the actual bomb ${ }^{14} \mathrm{C}$ inventories that are given by the FP curve. This conclusion is in agreement with the results of Naegler (2009). Second, the closeness of the results with FPL and RP in the 1990s illustrates how trying to reconcile models (FP) and data (RP) would call for a lower gas exchange rate. The results of these sensitivity studies imply that the formulation of the ${ }^{14} \mathrm{C}$ tracer in numerical models has to be adapted to the aim pursued. The global radiocarbon cycle needs to be addressed with the F (FP) method, which, by guaranteeing a full coherency between the ${ }^{14} \mathrm{C}$ and carbon air-sea exchanges, provides the actual ocean bomb ${ }^{14} \mathrm{C}$ inventory. This method is also fully relevant when investigating past or present $\Delta{ }^{14} \mathrm{C}$ distributions with the help of OGCMs. On the other hand, method R (RP) appears more appropriate when the purpose is to assess or calibrate upper ocean dynamics in models with the help of bomb ${ }^{14} \mathrm{C}$ distribution based on observations. This method is also relevant for the estimate of $\mathrm{CO}_{2}$ piston velocity. For this latter purpose, the model should be assessed or calibrated without the help of bomb ${ }^{14} \mathrm{C}$. Then one could take advantage of field estimates of the ocean bomb ${ }^{14} \mathrm{C}$ inventory to optimize the $\mathrm{CO}_{2}$ piston velocity with method $\mathrm{RP}$.

This work helps to resolve the large discrepancies between data-based estimates and model reconstructions of the bomb ${ }^{14} \mathrm{C}$ inventory in the ocean. The specification of similar time histories for the atmospheric and oceanic ${ }^{14} \mathrm{C}$ has limitations. Bomb ${ }^{14} \mathrm{C}$ inventories differ significantly, both in the 1970s and in the 1990s, between experiments where we adopted that assumption and those where we did not. Relaxing this constraint leads to bomb ${ }^{14} \mathrm{C}$ inventories that are usually larger than field estimates. Modeling studies could allow to overcome some of the difficulties inherent to field reconstruction (e.g. spatial coverage, pre-anthropogenic state). However, model results do not depend 


\section{The Ocean Bomb ${ }^{14} \mathrm{C}$ Inventory Revisited}

only on the gas exchange rate but also on the level of mixing (explicit and implicit through numerical scheme) and on the ventilation rate inherent to the model. OGCMs have deficiencies in reproducing the actual ocean ventilation rate on decadal to centennial timescales (e.g. Doney et al. 2004; Matsumoto et al. 2004), the level of vertical diffusion active in 3D OGCMs being probably too high (Duffy et al. 1997; England and Rahmstorf 1999; Oschlies 2000; Schmittner et al. 2009). Yet, this work suggests strategies allowing to gain advantage of the available data for either assessing the global carbon budget or estimating the air-sea exchange rate. Nevertheless, this problem might prove difficult to solve. Indeed, the processes involved in the ocean uptake of bomb ${ }^{14} \mathrm{C}$ (atmospheric $\mathrm{CO}_{2}$, wind exchange, mixing, and global overturning) are characterized by widely different timescales. Available field estimates provide information on the early stages of the uptake only $(\sim 30 \mathrm{yr})$. This is possibly too short a duration to allow for a clear discrimination among the processes.

\section{ACKNOWLEDGMENTS}

The author is grateful to A Winguth, E Maier-Reimer, and J-M Campin for kindly providing the 3D OGCM transport fields. Previous versions of the manuscript benefited much from comments by $\mathrm{J}$ Orr, G Munhoven, and 3 anonymous reviewers.

\section{REFERENCES}

Bacastow R, Maier-Reimer E. 1990. Ocean-circulation model of the carbon cycle. Climate Dynamics 4:95125.

Broecker WS, Peng T-H. 1974. Gas exchange rates between air and sea. Tellus 26:21-35.

Broecker WS, Gerard RD, Ewing M, Heezen BC. 1961. Geochemistry and physics of ocean circulation. In: Sears M, editor. Oceanography. Washington: AAAS. Publication 67. p 301-22

Broecker WS, Peng T-H, Ostlund G, Stuiver M. 1985. The distribution of bomb radiocarbon in the ocean. Journal of Geophysical Research 90:6953-70.

Broecker WS, Sutherland S, Smethie W, Peng T-H, Ostlund G. 1995. Oceanic radiocarbon: separation of the natural and bomb components. Global Biogeochemical Cycles 9:263-88.

Bryan F. 1987. Parameter sensitivity of primitive equation OGCMs. Journal of Physical Oceanography 17: 970-85.

Butzin M, Prange M, Lohmann G. 2005. Radiocarbon simulations for the glacial ocean: the effects of wind stress, Southern Ocean sea ice and Heinrich events. Earth and Planetary Science Letters 235:45-61.

Campin J-M, Goosse H. 1999. Parameterization of density-driven downsloping flow for a coarse-resolution ocean model in z-coordinate. Tellus A 51:412-30.

Campin J-M, Fichefet T, Duplessy J-C. 1999. Problems with using radiocarbon to infer ocean ventilation rates for past and present climates. Earth and Planetary Science Letters 165:17-24.

Craig H. 1969. Abyssal carbon and radiocarbon in the Pacific. Journal of Geophysical Research 74:5491506.

Deleersnijder E, Campin J-M. 1995. On the computation of the barotropic mode of a free-surface world ocean model. Annales Geophysicae 13:675-88.
Doney SC, Lindsay K, Caldeira K, Campin J-M, Drange H, Dutay J-C, Follows M, Gao Y, Gnanadesikan A, Gruber N, Ishida A, Joos F, Madec G, Maier-Reimer E, Marshall J, Matear R, Monfray P, Mouchet A, Najjar R, Orr J, Plattner G-K, Sarmiento J, Schlitzer R, Slater R, Totterdell I, Weirig M-F, Yamanaka Y, Yool A. 2004. Evaluating global ocean carbon models: the importance of realistic physics. Global Biogeochemical Cycles 18: GB3017, doi:10.1029/2003GB00215.

Druffel ER, Suess HE. 1983. On the radiocarbon record in banded corals: exchange parameters and net transport of ${ }^{14} \mathrm{CO}_{2}$ between atmosphere and surface ocean. Journal of Geophysical Research 88:1271-80.

Duffy PB, Caldeira K. 1995. Three-dimensional model calculation of ocean uptake of bomb ${ }^{14} \mathrm{C}$ and implications for the global budget of bomb ${ }^{14} \mathrm{C}$. Global Biogeochemical Cycles 9:373-5.

Duffy PB, Caldeira K, Selvaggi J, Hoffert MI. 1997. Effect of subgridscale mixing parameterizations on simulated distributions of natural ${ }^{14} \mathrm{C}$, temperature, and salinity in a three-dimensional ocean general circulation model. Journal of Physical Oceanography 27: 498-523.

England MH, Rahmstorf S. 1999. Sensitivity of ventilation rates and radiocarbon uptake to subgrid-scale mixing in ocean models. Journal of Physical Oceanography 29:2802-27.

Enting IG, Wigley TML, Heimann M. 1994. Future emissions and concentrations of carbon dioxide: Key Ocean/Atmosphere/Land Analyses. Technical Report 31. CSIRO.

Francey RJ, Allison C, Etheridge D, Trudinger CM, Enting IG, Leuenberger M, Langenfelds RK, Michel E, Steele LP. 1999. A 1000 year high precision record of $\delta^{13} \mathrm{C}$ in atmospheric $\mathrm{CO}_{2}$. Tellus B 51:170-93.

Goosse H, Brovkin V, Fichefet T, Haarsma R, Huybre- 


\section{A Mouchet}

chts P, Jongma J, Mouchet A, Selten F, Barriat P-Y, Campin J-M, Deleersnijder E, Driesschaert E, Goelzer H, Janssens Y, Loutre M-F, Morales Maqueda MA, Opsteegh T, Mathieu P-P, Munhoven G, Petterson E, Renssen H, Roche D, Schaeffer M, Tartinville B, Timmermann A, Weber SL. 2010. Description of the earth system model of intermediate complexity LOVECLIM version 1.2. Geoscientific Model Development 3:603-33.

Gruber N, Gloor M, Doney SC, Fletcher SEM, Dutkiewicz S, Follows MJ, Gerber M, Jacobson AR, Joos F, Lindsay K, Menemenlis D, Mouchet A, Mueller SA, Sarmiento JL, Takahashi T. 2009. Oceanic sources, sinks, and transport of atmospheric $\mathrm{CO}_{2}$. Global Biogeochemical Cycles 23: GB1005, doi:10.1029/ 2008 GB003349.

Heimann M, Maier-Reimer E. 1996. On the relations between the oceanic uptake of $\mathrm{CO}_{2}$ and its carbon isotopes. Global Biogeochemical Cycles 10:89-110.

Hesshaimer V, Heimann M, Levin I. 1994. Radiocarbon evidence for a smaller oceanic carbon dioxide sink than previously believed. Nature 370(6486):201-3.

Ito T, Marshall JC, Follows MJ. 2004. What controls the uptake of transient tracers in the Southern Ocean? Global Biogeochemical Cycles 18: GB2021, doi: 10.1029/2003GB002103.

Jain AK, Kheshgi HS, Hoffert MI, Wuebbles DJ. 1995. Distribution of radiocarbon as a test of global carbon cycle models. Global Biogeochemical Cycles 9:15366.

Joos F. 1994. Imbalance in the budget. Nature 370(6486): $181-2$.

Joos F, Bruno M. 1998. Long-term variability of the terrestrial and oceanic carbon sinks and the budgets of carbon isotopes ${ }^{13} \mathrm{C}$ and ${ }^{14} \mathrm{C}$. Global Biogeochemical Cycles 12:277-95.

Joos F, Orr JC, Siegenthaler U. 1997. Ocean carbon transport in a box-diffusion versus a general circulation model. Journal of Geophysical Research 102: $12,367-88$.

Keeling CD. 1981. Standardization of notations and procedures. 3.3 The modelling of rare isotopic carbon with regards to notation. In: Bolin B, editor. Carbon Cycle Modelling. New York: John Wiley \& Sons. p 89-101.

Keeling RF, Piper S, Bollenbacher A, Walker S. 2010. Monthly atmospheric ${ }^{13} \mathrm{C} /{ }^{12} \mathrm{C}$ isotopic ratios. In: Trends: A Compendium of Data on Global Change. Carbon Dioxide Information Analysis Center, Oak Ridge National Laboratory, US Department of Energy, Oak Ridge, Tennessee, USA.

Key RM, Kozyr A, Sabine C, Lee K, Wanninkhof R, Bullister J, Feely R, Millero F, Mordy C, Peng T-H. 2004. A global ocean carbon climatology: results from GLODAP. Global Biogeochemical Cycles 18: GB4031, doi:10.1029/2004GB002247.

Krakauer NY, Randerson JT, Primeau FW, Gruber N, Menemenlis D. 2006. Carbon isotope evidence for the latitudinal distribution and wind speed dependence of the air-sea gas transfer velocity. Tellus B 58:390-417.

Lassey KR, Enting IG, Trudinger CM. 1996. The earth's radiocarbon budget. Tellus $B$ 48:487-501.

Leboucher V, Orr J, Jean-Baptiste P, Arnold M, Monfray P, Tisnerat-Laborde N, Poisson A, Duplessy J-C. 1999. New accelerator mass spectrometry radiocarbon measurements on WOCE I6 section between Antarctica and South Africa. Radiocarbon 41(1):51-73.

Levin I, Naegler T, Kromer B, Diehl M, Francey R, Gomez-Pelaez A, Steele L, Wagenbach D, Weller R, Worthy D. 2010. Observations and modelling of the global distribution and long-term trend of atmospheric ${ }^{14} \mathrm{CO}_{2}$. Tellus B 62:26-46.

Lynch-Stieglitz J, Stocker TF, Broecker WS, Fairbanks RG. 1995. The influence of air-sea exchange on the isotopic composition of oceanic carbon: observations and modeling, Global Biogeochemical Cycles 9:65365.

Mahadevan A. 2001. An analysis of surface trends of bomb radiocarbon in the pacific. Marine Chemistry 73:273-90.

Maier-Reimer E. 1993. Geochemical cycles in an ocean general circulation model. Preindustrial tracer distributions. Global Biogeochemical Cycles 7:645-77.

Maier-Reimer E, Mikolajewicz U, Hasselmann K. 1993. Mean circulation of the Hamburg LSG OGCM and its sensitivity to the thermohaline surface forcing. Journal of Physical Oceanography 23:731-57.

Matsumoto K, Sarmiento JL, Key RM, Aumont O, Bullister JL, Caldeira K, Campin J-M, Doney SC, Drange H, Dutay J-C, Follows M, Gao Y, Gnanadesikan A, Gruber N, Ishida A, Joos F, Lindsay K, MaierReimer E, Marshall JC, Matear RJ, Monfray P, Mouchet A, Najjar R, Plattner G-K, Schlitzer R, Slater R, Swathi PS, Totterdell IJ, Weirig M-F, Yamanaka Y, Yool A, Orr JC. 2004. Evaluation of ocean carbon cycle models with data-based metrics. Geophysical Research Letters 31: L07303, doi:10.1029/ 2003GL018970.

Mikolajewicz U, Maier-Reimer E, Crowley JT, Kim K. 1993. Effect of Drake and Panamanian Gateways on the circulation of an ocean model. Palaeoceanography 8:4. doi:10.1029/93PA00893.

Mook WG, Bommerson JC, Staverman WH. 1974. Carbon isotope fractionation between dissolved bicarbonate and gaseous carbon dioxide. Earth and Planetary Science Letters 22:169-76.

Mouchet A. 2011. A 3D model of ocean biogeochemical cycles and climate sensitivity studies [PhD thesis]. Université de Liège, Liège, Belgium.

Mouchet A, François L. 1996. Sensitivity of a global ocean carbon cycle model to the circulation and to the fate of organic matter: preliminary results. Physics and Chemistry of the Earth 21:511-6.

Mouchet A, Deleersnijder E, Primeau F. 2012. The leaky funnel model revisited. Tellus A 64:19131, doi: 10.3402/tellusa.v64i0.19131. 


\section{The Ocean Bomb ${ }^{14} \mathrm{C}$ Inventory Revisited}

Müller SA, Joos F, Edwards NR, Stocker TF. 2006. Water mass distribution and ventilation time scales in a costefficient, three-dimensional ocean model. Journal of Climate 19/21:5479-99.

Müller SA, Joos F, Plattner G-K, Edwards NR, Stocker TF. 2008. Modeled natural and excess radiocarbon: sensitivities to the gas exchange formulation and ocean transport strength. Global Biogeochemical $\mathrm{Cy}$ cles 22: GB3011, doi:10.1029/2007GB003065.

Naegler T. 2009. Reconciliation of excess ${ }^{14} \mathrm{C}$-constrained global $\mathrm{CO}_{2}$ piston velocity estimates. Tellus $B$ 61:372-84.

Naegler T, Ciais P, Rodgers K, Levin I. 2006. Excess radiocarbon constraints on air-sea gas exchange and the uptake of $\mathrm{CO}_{2}$ by the oceans. Geophysical Research Letters 33: L11802, doi:10.1029/2005GL025408.

Orr J, Najjar R, Sabine C, Joos F. 2000. AbioticHOWTO. Ocean-Carbon Cycle Model Intercomparison Project (OCMIP). Internal OCMIP Report, LSCE/ CEA Saclay, Gif-sur-Yvette, France. 25 p.

Orr JC, Maier-Reimer E, Mikolajewicz U, Monfray P, Sarmiento JL, Toggweiler JR, Taylor NK, Palmer J, Gruber N, Sabine CL, Le Quéré C, Key RM, Boutin J. 2001. Estimates of anthropogenic carbon uptake from four three-dimensional global ocean models. Global Biogeochemical Cycles 15:43-60.

Oschlies A. 2000. Equatorial nutrient trapping in biogeochemical ocean models: the role of advection numerics. Global Biogeochemical Cycles 14:655-67.

Peacock S. 2004. Debate over the ocean bomb radiocarbon sink: closing the gap. Global Biogeochemical $\mathrm{Cy}$ cles 18: GB2022, doi:10.1029/2003GB002211.

Rodgers KB, Schrag DP, Cane MA, Naik NH. 2000. The bomb ${ }^{14} \mathrm{C}$ transient in the Pacific Ocean. Journal of Geophysical Research 105:8489-512.

Rubin SI, Key RM. 2002. Separating natural and bombproduced radiocarbon in the ocean: the potential alkalinity method. Global Biogeochemical Cycles 16: 1105, doi:10.1029/2001GB001432.

Sabine CL, Feely RA, Gruber N, Key RM, Lee K, Bullister JL, Wanninkhof R, Wong CS, Wallace DWR, Tilbrook B, Millero FJ, Peng TH, Kozyr A, Ono T, Rios AF. 2004. The oceanic sink for anthropogenic $\mathrm{CO}_{2}$. Science 305(5682):367-71.

Schmittner A, Urban NM, Keller K, Matthews D. 2009. Using tracer observations to reduce the uncertainty of ocean diapycnal mixing and climate carbon cycle projections. Global Biogeochemical Cycles 23: GB4009, doi:10.1029/2008GB003421.

Siegenthaler U. 1986. Carbon dioxide: its natural cycle and anthropogenic perturbation. In: Buat-Ménard P, editor. The Role of Air-Sea Exchange in Geochemical Cycling. NATO ASI Series, volume C185. Dordrecht: D. Reidel Publishing Company. p 209-47.

Siegenthaler U, Münnich KO. $1981 .{ }^{13} \mathrm{C} /{ }^{12} \mathrm{C}$ fractionation during $\mathrm{CO}_{2}$ transfer from air to sea. In: Bolin B, editor. Carbon Cycle Modelling. New York: John
Wiley \& Sons. p 249-257.

Stocker TF, Broecker WS, Wright DG. 1994. Carbon uptake experiments with a zonally-averaged global ocean circulation model. Tellus B 46:103-22.

Stuiver M, Polach HA. 1977. Discussion: reporting of ${ }^{14} \mathrm{C}$ data. Radiocarbon 19(3):355-63.

Stuiver M, Ostlund H, McConnaughey T. 1981. GEOSECS Atlantic and Pacific ${ }^{14} \mathrm{C}$ distribution. In: Bolin B, editor. Carbon Cycle Modelling. New York: John Wiley \& Sons. p 201-21.

Sweeney C, Gloor E, Jacobson AR, Key RM, McKinley G, Sarmiento JL, Wanninkhof R. 2007. Constraining global air-sea gas exchange for $\mathrm{CO}_{2}$ with recent bomb ${ }^{14} \mathrm{C}$ measurements. Global Biogeochemical Cycles 21: GB2015, doi:10.1029/2006GB002784.

Takahashi T, Sutherland SC, Wanninkhof R, Sweeney C, Feely RA, Chipman DW, Hales B, Friederich G, Chavez F, Watson A, Bakker DCE, Schuster U, Metzl $\mathrm{N}$, Yoshikawa-Inoue H, Ishii M, Midorikawa T, Nojiri Y, Sabine C, Olafsson J, Arnarson TS, Tilbrook B, Johannessen T, Olsen A, Bellerby R, Körtzinger A, Steinhoff T, Hoppema M, de Baar HJW, Wong CS, Delille B, Bates NR. 2009. Climatological mean and decadal changes in surface ocean $\mathrm{pCO}_{2}$, and net seaair $\mathrm{CO}_{2}$ flux over the global oceans. Deep-Sea Research II 56:554-77.

Toggweiler JR, Samuels B. 1993. New radiocarbon constraints on the upwelling of abyssal water to the ocean's surface. In: Heimann M, editor. The Global Carbon Cycle. NATO ASI Series, volume I15. Berlin: Springer Verlag. p 333-66.

Toggweiler JR, Dixon K, Bryan K. 1989a. Simulations of radiocarbon in a coarse-resolution world ocean model. 1. Steady state prebomb distributions. Journal of Geophysical Research 94:8217-42.

Toggweiler JR, Dixon K, Bryan K. 1989b. Simulations of radiocarbon in a coarse-resolution world ocean model. 2. Distributions of bomb-produced carbon 14. Journal of Geophysical Research 94:8243-64.

Trenberth KE, Olson JG, Large WG. 1989. A global ocean wind stress climatology based on ECMWF analyses. Technical Report NCAR/TN-338+STR. National Center for Atmospheric Research, Boulder, Colorado, USA.

Vogel JC, Grootes PM, Mook WG. 1970. Isotopic fractionation between gaseous and dissolved carbon dioxide. Zeitschrift für Physik 230:225-38.

Wanninkhof R. 1992. Relationship between wind speed and gas exchange over the ocean. Journal of Geophysical Research 97:7373-82.

Watson AJ, Liss PS. 1998. Marine biological controls on climate via the carbon and sulfur geochemical cycles. Philosophical Transactions of the Royal Society of London 353:41-51.

Weiss R. 1974. Carbon dioxide in water and seawater: the solubility of a non-ideal gas. Marine Chemistry 2: 203-15. 